\title{
MEIO AMBIENTE E ESTRATÉGIA: UM ESTUDO MULTICASO NO SETOR VITIVINÍCOLA DA REGIÃO CENTRAL DO RIO GRANDE DO SUL SOB A PERSPECTIVA DA TEORIA INSTITUCIONAL ENVIRONMENT AND STRATEGY:
A MULTICASE STUDY IN THE WINEINDUSTRY
FROM CENTRAL REGION OF RIO GRANDE
DO SUL STATEBRAZIL, UNDER THE
PERSPECTIVE OF INSTITUTIONAL THEORY
}

Recebido 16-11-2013 Aceito 20-04-2014

Diego Echevenguá Borges ${ }^{1}$ Luiz Cunha Dutra ${ }^{2}$ Flávia Luciane Scherer ${ }^{3}$

\section{RESUMO}

O presente estudo concentra esforços para identificar e analisar quais respostas estratégicas (OLIVER, 1991) três vinícolas da região central do Rio Grande do Sul acionaram frente às pressões do ambiente institucional relativas ao gerenciamento de práticas ambientalmente corretas. Ainda, pretende-se identificar se há resquícios de isomorfismo entre as ações das vinícolas objetos de estudo diante das pressões institucionais. Para tanto, foram revisados temas relativos à teoria institucional, quanto às respostas estratégicas e pressões ambientais, bem como questões sobre pressões oriundas do ambiente institucional relacionadas com o gerenciamento de práticas ambientalmente corretas em sítios eletrônicos, artigos acadêmicos etc. Foi realizado um estudo qualitativo, tendo como instrumento, para coletar os dados primários junto a três vinícolas que compunham a amostra, um questionário semiestruturado com três questões abertas. Os resultados mostram que, frente à pressão oriunda do governo e dos consumidores, as três vinícolas tendem a adotar comportamentos isomórficos, conformando-se às exigências de ambos os constituintes. Conclui-se que as três vinícolas, mesmo não buscando a certificação ISO 14001:2004 ou não percebendo a preocupação do consumidor com relação à gestão ambiental, trabalham de maneira proativa, mantendo bom relacionamento com os órgãos fiscalizadores, para que suas ações não venham a afetar o meio ambiente.

Palavras-chave: teoria institucional, pressões do ambiente institucional, repostas estratégias, meio ambiente, constituintes externos.

\footnotetext{
${ }^{1}$ Possui graduação em Administração pela Universidade de Caxias do Sul - UCS. Atualmente é mestrando em Administração pela Universidade Federal de Santa Maria - UFSM e doutorando em Administração pela Universidade Federal de Minas Gerais - UFMG. Belo Horizonte, Minas Gerais, Brasil. E-mail: diego.e.borges@hotmail.com

${ }^{2}$ Possui graduação em Farmácia e mestrado em Ciência e Tecnologia dos Alimentos pela Universidade Federal de Santa Maria - UFSM. Atualmente é secretario da pós-graduação em Administração da Universidade Federal de Santa Maria- UFSM. Santa Maria, Rio Grande do Sul, Brasil. E-mail: luizcunhadutra@gmail.com.

${ }^{3}$ Possui graduação em Administração pela Universidade Federal de Santa Maria - UFSM, mestrado em Administração pela Universidade Federal de Santa Catarina - UFSC e doutorado em Administração pela Universidade Federal de Minas Gerais - UFMG. Atualmente é professora na Universidade Federal de Santa Maria - UFSM. Santa Maria, Rio Grande do Sul, Brasil. E-mail: flaviascherer@ globo.com
} 


\section{ABSTRACT}

This study focuses efforts in identifying and analyzing which strategic responses (Oliver, 1991) three wineries from the central region of Rio Grande do Sul state triggered faced with the pressures of the institutional environment that are related with environmentally management practices. Still, it is intended to identify whether there are vestiges of isomorphism between the actions of the wineries objects of study in the face of institutional pressures. Therefore, we reviewed issues related to institutional theory, in its strands strategic responses and environmental pressures, as well as sought in their websites, academic papers, etc., Pressures arising from the institutional environment related to environmentally management practices. We conducted a qualitative study, and as a tool to collect primary data along the three wineries that made the sample we conducted a semi-structured interviews with three open questions. The results show that in the case of develop pressure from the government and consumers, the three wineries tend to adopt isomorphic behaviors, conforming to the requirement of both constituents. We conclude that the three wineries even not seeking ISO 14001:2004 certification, or not realizing consumer concern regarding environmental management, they work proactively maintaining good relationships with regulatory agencies so that their actions will not to affect the environment.

Keywords: institutional theory, environmental pressures, strategic responses, environment, external constituents.

\section{INTRODUÇÃO}

Em virtude do crescente nível de competitividade advindo com a globalização, as organizações não mais se diferenciam no mercado apenas fazendo uso eficiente de seus ativos, tais como conhecimento e/ou tecnologia. Assim, o ambiente institucional e as diretrizes impostas por seus constituintes (como, por exemplo, legisladores, consumidores e associações do setor) devem ser consideradas pelas organizações em seus processos estratégicos para obter legitimidade e, consequentemente, sobreviver no mercado.

Considerando o setor vitivinícola, os interesses que a sociedade civil compartilha (consumindo produtos de empresas preocupadas com o impacto de suas atividades no meio ambiente, por exemplo), assim como as imposições oriundas de legisladores (como formulando leis e resoluções, por exemplo) e associações de setor (tal como estabelecendo certificações), impactam diretamente as ações praticadas pelas vinícolas no mercado, pois o não cumprimento ou o desvio imprudente das forças do ambiente institucional pode refletir na deterioração da imagem das empresas e, em consequência disso, na perda de competitividade (FONSECA E MACHADODA-SILVA, 2002; MEYER e ROWAN, 1977).

No entanto, Christ e Burritt (2013), apoiados no estudo de Ene et al (2013) e Gabzdylova et al (2009), expõem que a indústria vitivinícola não sofre o mesmo grau de supervisão e controle do que as indústrias química e mineral, pois é rotulada pelos stakeholders como sendo não poluidora, passando, portanto, a imagem de ser "verde e limpa". Perante esses motivos, as implicações das atividades vitivinícolas junto ao meio ambiente permanecem inexploradas (CHRIST; BURRITT, 2013).

Nesse contexto dinâmico no qual as organizações devem levar em consideração as requisições do ambiente institucional caso queiram legitimar suas ações frente aos consumidores e órgãos governamentais, o uso da teoria institucional para analisar como estas se relacionam com os requerimentos avindos do ambiente externo se apresenta como importante ferramenta, visto que seu aporte teórico permite analisar e descrever tanto as estratégias que as organizações utilizam para se adequar às pressões do ambiente quanto as táticas organizacionais direcionadas ao desvio ou à manipulação das instituições e dos constituintes.

Diante disso, o presente estudo concentra esforços para identificar e analisar quais res- 
postas estratégicas (OLIVER, 1991) três vinícolas da região central do Rio Grande do Sul acionaram frente às pressões do ambiente institucional relativas ao gerenciamento de práticas ambientalmente corretas. Pretende-se, ainda, identificar se há resquícios de isomorfismo entre as ações das vinícolas objetos de estudo diante das pressões ambientais.

No que se refere à estrutura geral do estudo, apresenta-se, como primeiro elemento elencado, o referencial teórico, abordando a teoria institucional e duas das suas vertentes: pressões ambientais - com a contextualização das respectivas pressões delineadas no presente trabalho como variáveis independentes - e as possíveis repostas estratégicas acionadas pelas organizações frente às pressões ambientais. Logo após, delineia-se o método utilizado; apresentam-se os resultados; e, por último, expõe-se a conclusão do estudo.

\section{QUADRO TEÓRICO}

\subsection{Teoria institucional}

Scott (2008) define instituição como estruturas e padrões de comportamento, constituídos por elementos regulativos, normativos e culturais-cognitivos que proveem estabilidade e significado para o comportamento social, mas estão sujeitos a processos de mudanças incrementais e descontínuas. Dentre as linhas de pesquisa que compõem a esfera da teoria institucional, a presente investigação faz uso dos estudos de Scott (2008), que apresenta os três pilares institucionais, das contribuições de Dimaggio e Powell (1991) e Meyer e Rowan (1977), os quais atentam para a análise da homogeneização das formas e práticas organizacionais diante das pressões do ambiente institucional, e do estudo de Oliver (1991), que delineia cinco possíveis respostas estratégicas organizacionais que variam desde a conformação às instituições até a sua manipulação.

\subsection{Pressões ambientais e isomorfismo}

Pressões ambientais são entendidas como eventos que ocorrem no ambiente institucional e que pressionam as organizações para que tornem suas práticas e configurações isomórficas. Nesse processo, as instituições, por meio de seus elementos regulativos, normativos e culturalcognitivos, concebem as pressões visando prover, também, estabilidade e significado para a vida social (DIMAGGIO; POWELL, 1991; SCOTT, 2008).

Segundo Scott (2008), instituições reguladoras pressionam as organizações por meio de sua capacidade de estabelecer regras, inspecionar a conformidade de determinados aspectos relacionados com conduta social e, quando necessário, manipular sanções - recompensas ou punições - em uma tentativa de influenciar o comportamento futuro. A sociedade e as organizações, pelo sentimento de medo ou culpa, obedecem às leis ou regras emanadas do governo porque o caráter coercitivo e punitivo destas Ihes impõem restrições com vistas a manter a estabilidade social.

Instituições normativas são compartilhadas por determinados grupos pelo fato de estas possuírem valores e normas que conferem aos grupos credibilidade e certificação frente à sociedade. Quanto às normas, estas especificam como as coisas devem ser feitas, definindo, então, meios legítimos para alcançar fins que sejam substanciados de valor (SCOTT, 2008).

As instituições culturais cognitivas diferenciam-se das demais instituições pelo fato de seus elementos serem seguidos de maneira ortodoxa pela sociedade, pois são interpretados como constituintes da natureza da realidade social e também como modelos que servem para construir significados. Sendo assim, o pilar cultural-cognitivo é o mais profundo porque seu en- 
tendimento se encontra no pré-consciente, sendo dado como verdadeiro (SCOTT, 2008).

Aprofundando o entendimento sobre a relação organização-ambiente, Meyer e Rowan (1977) argumentam que as estruturas formais de muitas organizações na sociedade pós-industrial, de certa forma, refletem os mitos de seus ambientes institucionais em vez das demandas de suas atividades laborais. Para os autores, organizações cujas estruturas se tornam padronizadas ou isomórficas com os mitos do ambiente institucional - em contraste com aquelas que primariamente se estruturam levando em consideração as demandas de produção e trocas - acabam diminuindo o controle interno e a coordenação para obter legitimidade no ambiente de atuação, fato que aumenta as fontes de recursos e, por consequência, a competitividade organizacional.

Nesse sentido, o isomorfismo nas organizações pode ser entendido como um processo pelo qual as organizações tornam seus processos e suas ações semelhantes pelo fato de serem pressionadas pelo ambiente. $\mathrm{O}$ isomorfismo ocorre por meio de três mecanismos: coercitivo, normativo e mimético (DIMAGGIO; POWELL, 1991).

Segundo DiMaggio e Powell (1991), o isomorfismo coercitivo resulta de pressões formais e informais exercidas por organizações, das quais a organização pressionada é dependente, de expectativas culturais vindas da sociedade. Tais pressões podem ser entendidas como força, persuasão ou convite para unirem-se em conspiração.

O isomorfismo normativo deriva, primariamente, da profissionalização. Profissões estão sujeitas às mesmas pressões coercitivas e miméticas que as organizações, pois ainda que os profissionais de departamentos diferentes de uma empresa possam diferir entre si, geralmente, eles exibem muita similaridade com profissionais de outras organizações que exercem funções semelhantes às suas (DIMAGGIO E POWELL, 1991).

$\mathrm{O}$ isomorfismo mimético, por sua vez, tem a ver com a imitação. É a incerteza oriunda de objetivos organizacionais ambíguos que leva organizações a copiarem outras organizações bem-sucedidas, tomando-as como modelos (SCHERER, 2007; DIMAGGIO; POWELL, 1991).

No entanto, institucionalistas como Machado da Silva, Fonseca e Crubelatte (2005) ressaltam que conceber subjetivamente o ambiente implica reconhecer que indivíduos, grupos e organizações podem visualizar o mesmo ambiente em que mantêm suas atividades diárias de maneira diferente. Assim, parte do aporte teórico institucional busca analisar, sob a perspectiva da agência, o comportamento organizacional dentro de seu campo de atuação (OLIVER, 1991; GRAEFF, 2005; HASHIMOTO; 2005; SVEJENOVA, MAZZA, e PLANELLAS, 2007).

\subsection{Estratégia e repostas estratégicas}

No que tange à caracterização de estratégia dentro da fronteira institucionalista, Hashimoto (2005) coloca que o estrategista elabora suas ações e, concomitantemente, percebe atuais e possíveis normas, regras e crenças que vêm a se institucionalizar na sociedade com o intuito de elaborar planos para responder adequadamente a estas. Oliver (1991), disposta a entender como as organizações respondem estrategicamente às pressões ambientais, propôs o modelo de respostas estratégicas, cuja principal característica é sua análise da relação ambiente-organização sob a perspectiva voluntarista da empresa.

O modelo desenvolvido por Oliver (1991) enfatiza que respostas estratégicas das organizações visando defender seus interesses econômicos e/ou sociais frente às pressões ambientais podem variar desde respostas estratégicas voltadas à conformidade até estratégias resistentes, com nuances de variabilidade diante das instituições. Com relação à primeira resposta, aquiescer, Oliver (1991) ressalta que, embora organizações normalmente adiram às pressões ambientais, a 
aquiescência pode se configurar em diferentes táticas: hábito, imitação e obediência. A seguir, no Quadro 1, apresenta-se a descrição de cada uma das referidas táticas:

Quadro 1 - Táticas que compõem a resposta estratégica aquiescer.

\begin{tabular}{|c|l|}
\hline Táticas & \multicolumn{1}{c|}{ Descrição } \\
\hline Hábito & $\begin{array}{l}\text { Seguem-se normas invisíveis e tidas como certas. } \\
\text { Refere-se à adesão inconsciente ou cega a regras ou } \\
\text { valores tidos como verdadeiros. }\end{array}$ \\
\hline Imitação & $\begin{array}{l}\text { Imitam-se modelos já institucionalizados. Conscien- } \\
\text { te ou inconscientemente, imitam-se modelos institu- } \\
\text { cionais bem-sucedidos. }\end{array}$ \\
\hline Obediência & $\begin{array}{l}\text { Obedecem-se às regras e aceitam-se as normas. É } \\
\text { uma forma de complacência consciente a normas, } \\
\text { valores e crenças. }\end{array}$ \\
\hline
\end{tabular}

Fonte: elaborado a partir de Oliver (1991).

A segunda resposta estratégica, comprometer, de acordo com Oliver (1991), é tomada pelas organizações em situações em que elas consideram a conformidade desagradável ou impraticável. Nessas circunstâncias, as organizações podem utilizar as táticas de equilibrar, pacificar ou barganhar. A seguir, no Quadro 2, apresenta-se a descrição de cada uma das referidas táticas.

Quadro 2. Táticas que compõem a resposta estratégica comprometer.

\begin{tabular}{|c|l|}
\hline Táticas & \multicolumn{1}{|c|}{ Descrição } \\
\hline Equilibrar & $\begin{array}{l}\text { Equilibram-se as expectativas dos públicos múltiplos. } \\
\text { Procura-se acomodar as demandas institucionais de } \\
\text { múltiplos constituintes em resposta às pressões am- } \\
\text { bientais. }\end{array}$ \\
\hline Pacificar & $\begin{array}{l}\text { Acomodam-se e apaziguam-se os elementos institu- } \\
\text { cionais. Por meio dessa tática, as organizações con- } \\
\text { formam-se parcialmente às expectativas de um ou } \\
\text { mais constituintes. }\end{array}$ \\
\hline Barganhar & $\begin{array}{l}\text { Negocia-se com constituintes externos. Barganhar } \\
\text { envolve o esforço organizacional para obter conces- } \\
\text { sões dos constituintes externos. }\end{array}$ \\
\hline
\end{tabular}

Fonte: elaborado a partir de Oliver (1991)

A terceira resposta estratégica, fugir, é entendida por Oliver (1991) como uma tentativa da organização de evitar a conformidade ao escapar de regras ou expectativas do ambiente institucional. No campo da resposta fugir, estão acessíveis aos agentes organizacionais as táticas de ocultação, proteção e escape. Apresenta-se, no Quadro 3, a exemplificação das táticas mencionadas.

Quadro 3: Táticas que compõem a resposta estratégica fugir.

\begin{tabular}{|c|l|}
\hline Táticas & \multicolumn{1}{c|}{ Descrição } \\
\hline Ocultação & $\begin{array}{l}\text { Disfarça-se a não conformidade. Segundo a autora, a tática de esconder envolve } \\
\text { mascarar a não conformidade por trás da aparente aquiescência. }\end{array}$ \\
\hline Proteção & $\begin{array}{l}\text { Afasta-se das conexões institucionais. Esta tática está relacionada com a busca por } \\
\text { diminuir a inspeção ou avaliação de constituintes. }\end{array}$ \\
\hline Escape & $\begin{array}{l}\text { Mudar objetivos, atividades ou domínios. A organização pode ter a necessidade } \\
\text { de sair do local em que a pressão está sendo exercida ou alterar significativamente } \\
\text { seus objetivos, suas atividades ou seus domínios para evitar a necessidade de se } \\
\text { conformar. }\end{array}$ \\
\hline
\end{tabular}

Fonte: elaborado a partir de Oliver (1991). 
A quarta resposta estratégica, desafiar, é a forma mais ativa de resistência aos processos institucionais. As três táticas que compõem essa resposta estratégica são: despistar, recusar e atacar. No Quadro 4, descrevem-se as referidas táticas.

Quadro 4: Táticas que compõem a resposta estratégica desafiar.

\begin{tabular}{|c|l|}
\hline Táticas & \multicolumn{1}{|c|}{ Descrição } \\
\hline Despistar & $\begin{array}{l}\text { Ignoram-se normas ou valores explícitos. É utilizada } \\
\text { quando as organizações percebem as instituições } \\
\text { como fracas ou divergentes dos objetivos organiza- } \\
\text { cionais. }\end{array}$ \\
\hline Recusa & $\begin{array}{l}\text { Contestam-se regras e normas. Organizações são } \\
\text { mais propensas a desafiar as normas institucionali- } \\
\text { zadas quando se pode demonstrar que a racionalida- } \\
\text { de envolvida não é mais eficiente para determinada } \\
\text { situação. }\end{array}$ \\
\hline Ataque & $\begin{array}{l}\text { Atacam-se as fontes de pressões institucionais. É to- } \\
\text { mada quando organizações sentem que seus direi- } \\
\text { tos, seus privilégios e sua autonomia estão correndo } \\
\text { riscos. }\end{array}$ \\
\hline
\end{tabular}

Fonte: elaborado a partir de Oliver (1991).

A quinta resposta estratégica, manipular, de acordo com Oliver (1991), é uma tentativa oportuna e propositada de cooptar, influenciar ou controlar as pressões ambientais e as avaliações externas. As três táticas que compõem essa resposta estratégica são cooptação, influência e controle. No Quadro 5, descrevem-se as referidas táticas.

Quadro 5: Táticas que compõem a resposta estratégica comprometer

\begin{tabular}{|c|l|}
\hline Táticas & \multicolumn{1}{c|}{ Descrição } \\
\hline Cooptação & $\begin{array}{l}\text { Importar constituintes influentes. A cooptação tem a intenção de } \\
\text { neutralizar a oposição institucional e aumentar a legitimidade. }\end{array}$ \\
\hline Influência & $\begin{array}{l}\text { Configurar valores e critérios. É dirigida geralmente a valores e } \\
\text { crenças institucionalizados ou definições e critérios de práticas ou } \\
\text { performances já aceitas. }\end{array}$ \\
\hline Controle & $\begin{array}{l}\text { Dominam-se os processos e os constituintes institucionais. Dirige- } \\
\text { se esforço para dominar e exercer poder sobre os constituintes ex- } \\
\text { ternos que pressionam as organizações. }\end{array}$ \\
\hline
\end{tabular}

Fonte: elaborado a partir de Oliver (1991).

Entende-se, a partir o exposto, que as três vinícolas objetos de estudo situadas na região central do Estado podem ser caracterizadas como organizações que, ao mesmo tempo em que sofrem pressões do ambiente institucional na forma de legislações ambientais e de certificações de qualidade estabelecidas pelas associações do setor e pelas requisições dos consumidores por produtos ambientalmente corretos, utilizam seu poder de agência para responder às pressões de acordo com seus interesses e objetivos (WENDLER, 2009; FLINT e GOLICIC, 2009, DODDS et al. 2007, SINHA E AKORIEE, 2010, FORBES et al. 2010, CHRIST e BURRITT, 2013).

\section{METODOLOGIA}

Quanto aos fins, a pesquisa caracteriza-se como de natureza descritiva e abordagem qualitativa. No que se refere aos meios, faz-se uso do estudo de casos múltiplos (YIN, 2001).

Como fonte de dados primários, foram realizadas entrevistas semiestruturadas com os 
proprietários de três vinícolas da região central do Estado. As entrevistas ocorreram em corte transversal nos meses de abril e maio de 2013 e foram guiadas por um roteiro (protocolo) preestabelecido (YIN, 2001). O aporte de informações incluídas no protocolo foi obtido por meio de documentos, fotos, vídeos, histórias de vida, entrevistas, relatórios de pesquisa, arquivos de propriedade das vinícolas em estudo etc.

As entrevistas foram transcritas e combinadas com outras fontes de dados presentes no protocolo de pesquisa. Após essa etapa, partiu-se para a análise dos dados, utilizando a técnica de análise de conteúdo proposta por Bardin (1977). Nessa fase, foram quantificados e analisados a presença, os significados e os relacionamentos de palavras e conceitos nas entrevistas empreendidas, o que possibilitou a realização de inferências a partir das mensagens codificadas.

\subsection{Estruturação das questões de pesquisa}

A sustentabilidade tornou-se um termo importante não só do ponto de vista ambiental, mas também pelo viés político, econômico e social. Nesse contexto, legisladores, associações de setor e a sociedade civil, atuando de maneira interdependente, desenvolvem suas leis e normas com o intuito de guiar a expansão do setor vitivinícola em direção a um caminho que não agrida o meio ambiente. No entanto, no Brasil, a inserção da gestão sustentável nos processos organizacionais ainda é recente e não acontece em iguais proporções entre os setores, porque a demanda dos constituintes pode variar de acordo com o setor, o mercado e a localização da empresa (BARATA, 2007 apud CALLADO, 2010; SZOLNOCKI, 2013; DODDS et al. 2007).

A partir da revisão bibliográfica, delinearam-se três pressões oriundas do ambiente institucional com o intuito de identificar em que medida as vinícolas estão respondendo ao desafio de operacionalizar a crescente demanda de produtos e processos ambientalmente corretos. A primeira pressão refere-se à necessidade de inserir a gestão ambiental nas práticas vitivinícolas em função do aumento do controle de legisladores e órgãos fiscalizadores (Fepam e IBAMA, por exemplo). Como a legislação ambiental no Brasil é ampla e fragmentada, com legislações esparsas para água, solo, fauna e flora (WENDLER, 2009), tomou-se como base a Lei n.o 9.605, de 12 de fevereiro de 1998, que dispõe sobre ações penais e administrativas derivadas de condutas e atividades lesivas ao meio ambiente e dá outras providências. De acordo a tipologia de Scott (2008), essa pressão pode ser caracterizada como regulatória, pois se trata de uma lei criada pelo governo que é dotada de elementos coercitivos e punitivos.

Delimitou-se como segunda pressão ambiental a crescente adoção do certificado ISO 14001:2004 por vinícolas brasileiras, tais como a vinícola Almadén e Aurora, e também por vinícolas internacionais (FLINT E GOLICIC, 2009, DODDS et al. 2007, MIOLO WINEGROUP, 2009;VINICOLA AURORA, 2006; HUGHEY, TAIT E CONNEL, 2005). Segundo a classificação de Scott (2008), essa pressão pode ser caracterizada como de ordem normativa, porque o crescente compartilhamento da referida certificação dentro da indústria vitivinícola abre espaço para que ocorra uma distinção entre vinícolas certificadas, que adquirem maior credibilidade frente ao mercado e à sociedade, e aquelas não certificadas e, portanto, menos creditadas e reconhecidas.

No que se refere à terceira pressão, esta se relaciona ao fato de os consumidores em geral e de os consumidores de vinho em específico estarem cada vez mais preocupados com os efeitos das práticas de produção agrícola sobre o meio ambiente, conjuntura que os direciona a demandar vinhos ambientalmente corretos (FORBES et al. 2010, ORGANIZAÇÃO INTERNACIONAL DA VINHA E DO VINHO-OIV, 2012). Tomando como base o pensamento de Scott (2008), a pressão mencionada é de ordem cultural-cognitiva, porque seus elementos são atualmente interpretados 
como constituintes da natureza da realidade social.

Apoiando-se no estudo de Delmas e Toffel (2005), ressalta-se que foram delineadas pressões ambientais provenientes de questões ligadas ao meio ambiente porque estas oferecem um rico contexto de estudo, já que, tanto constituintes (como legisladores e grupos ativistas) que atuam fora do âmbito do mercado como aqueles (por exemplo associações de setor, clientes e fornecedores) que operam diretamente nesse âmbito, exercem pressões para que as empresas adotem práticas sustentáveis, ainda que estas não estejam institucionalizadas - como é o caso da adoção da certificação da ISO 14001:2004, que não é um requerimento com caráter regulatório e que não possui um amplo consenso sobre sua real eficácia.

Dado que as organizações recebem pressões ambientais oriundas de múltiplos constituintes, os quais direcionam diferentes mecanismos para demandar ações sustentáveis das organizações - como, por exemplo, no caso dos consumidores que buscam produtos de empresas ambientalmente responsáveis ou de legisladores que estabelecem punições com base em leis federais -, entende-se que analisar as respostas das três vinícolas objetos de estudo permitirá a retratação do modo como estas respondem a cada uma das pressões delineadas.

\subsection{Categorias analíticas}

Buscando analisar o conteúdo das pressões ambientais para, posteriormente, situá-las em algum dos pilares institucionais de Scott (2008), desenvolveu-se a categoria analítica pressões ambientais, composta das seguintes subcategorias de pressão: regulatória, normativa e culturalcognitiva. Delineiam-se, a seguir, a conceituação utilizada para a referida categoria e o modo como esta será operacionalizada com vistas a analisar as três pressões delineadas:

definição constitutiva (DC) - eventos que ocorrem no ambiente institucional, que pressionam as organizações para que se tornem mais homogêneas. Nesse processo, as instituições regulativas, normativas e culturais-cognitivas que emergem dos três pilares institucionais, associadas com outras atividades e recursos, pressionam a sociedade visando prover estabilidade e significado para a vida social (DIMAGGIO e POWELL, 1991; SCOTT, 2008); $\quad$ definição operacional (DO) - será operacionalizada por meio de análise documental, assim como da análise do conteúdo das entrevistas semiestruturadas com cada empreendedor vitivinícola que possui papel significativo em sua organização.

Para analisar o conteúdo das repostas dos três empreendedores objeto de estudo, desenvolveu-se a categoria analítica respostas estratégicas, a qual é dotada de cinco subcategorias: aquiescer, comprometer, fugir, desafiar e manipular. A seguir, apresentam-se a conceituação utilizada para a referida categoria e o modo como esta será operacionalizada com vistas a analisar o conteúdo das respostas dadas às pressões ambientais:

DC - ações tomadas pelas organizações visando defender seus interesses frente às pressões ambientais. As respostas estratégicas podem variar desde a conformidade aos padrões institucionais já sedimentados no ambiente até a manipulação dos agentes organizacionais, dependendo das pressões oriundas do ambiente institucional dirigidas e/ou dos objetivos traçados pelas organizações em seu planejamento (OLIVER, 1991);

DO - será operacionalizada por meio da análise de conteúdo das entrevistas semiestruturadas com cada empreendedor vitivinícola que possui papel significativo em sua organização. 


\subsection{Ambiência de pesquisa}

Foram pesquisadas três vinícolas inseridas no contexto socioeconômico da região central do Rio Grande do Sul. A escolha do contexto a ser estudado emergiu ao analisar o estudo de Dutra (1998), o qual diagnosticou o setor vitivinícola da região central com o intuito de identificar como as vinícolas gerenciavam seus resíduos e efluentes. Os resultados do trabalho do autor apontaram que as vinícolas não davam um tratamento adequado aos seus dejetos. Sendo assim, percebe-se que uma nova análise do setor vitivinícola na região central do Estado, passados 15 anos, é oportuna visto que se pode verificar como as vinícolas estão reagindo aos crescentes esforços de constituintes em prol da sustentabilidade ambiental.

A seguir, apresenta-se a descrição de cada uma das vinícolas objetos de estudo. Como forma de manter o sigilo das empresas pesquisadas, estas serão caracterizadas como Vinícola A, Vinícola B e Vinícola C.

A vinícola $A$ é de pequeno porte e atua no mercado vitivinícola há 15 anos. O empreendimento possui dois hectares de vinhedos, produzindo vinhos finos e de mesa, além de suco natural de uva e vinho espumante. Tal como a vinícola A, a Vinícola B é caracterizada como de pequeno porte e atua no mercado há 23 anos. Possuindo três hectares de vinhedos, a vinícola produz vinho finos e espumante. No que tange à vinícola $C$, esta é caracterizada como de pequeno porte, atuando no mercado desde 1997. Com relação aos seus vinhedos, estes alcançam o total de 12 hectares. A vinícola oferece vinhos finos, vinhos de mesa e espumante.

\section{RESULTADOS E DISCUSSÃO}

Feita o levantamento de dados secundários, procede-se, nessa etapa, à análise das pressões ambientais delineadas, tendo como base o modelo de respostas estratégicas de Oliver (1991). A seguir, apresentam-se as referidas pressões ambientais.

A Lei $n$. 9.605, de 12 de fevereiro de 1998, dispõe sobre ações penais e administrativas derivadas de condutas e atividades lesivas ao meio ambiente e dá outras providências. Como já ressaltado, essa pressão, de acordo com a classificação de Scott (2008), pode ser caracterizada como regulatória, pois se trata de uma lei criada pelo governo que é dotada de elementos coercitivos e punitivos. Com base nas entrevistas, pode-se averiguar a incidência do caráter regulador:

A gente faz as coisas de acordo com as normas e com as leis, tanto que, quando eu fui fazer a cantina, eu estudei como tinha que ser e tal. Quando eu fui na agricultura e o pessoal me disse que se todo mundo fosse que nem eu, não teria problema. A gente coloca no pátio a casca de uva, uma grande camada de casca com calcário. O calcário é utilizado pra equilibrar. Esse processo gera um ótimo adubo (Vinícola A).

Não sai nada de ruim daqui. Vai tudo para um local apropriado lá pra cima. A Fepam veio aqui e simplesmente me elogiou. Porque eu não ponho nada fora. O bagaço, tudo é aproveitado. $\mathrm{O}$ bagaço eu ponho num buraco que amanhã e depois vira adubo. $\mathrm{O}$ bagaço eu levo nos cocho e meus búfalos comem tudo. Então não vai pro meio ambiente (Vinícola B).

A vinícola tem a legalização da Fepam. Quando eu começo a operar, eu preciso da licença de operação que é renovada a cada cinco anos. Eu nunca me preocupei com cada uma das leis. Porque nessas licenças, na prévia, de instalação e operação, já veem todos os parâmetros que você precisa controlar. A partir disso que a gente segue. Sempre temos cuidado pra não jogar nada. [...] Quando é volume muito grande de borra, a gente recolhe em umas bombonas específicas pra isso, levando-as depois para o vinhedo e faz lá a compostagem. [...] Então não sai água sem passar por esses sistemas de captação (Vinícola C). 
Analisando o conteúdo das repostas, percebe-se que, de maneira isomórfica (DIMAGGIO e POWELL, 1991), todas as vinícolas acionam a estratégia aquiescer e a tática obedecer (OLIVER, 1991), pois estas se conformam à pressão ambiental, conscientes do caráter obrigatório da legislação e da importância desta para o controle dos impactos de suas práticas sobre o meio ambiente (GABZDYLOVA, RAFFENSPERGER e CASTKA, 2009; SINHA E AKORIEE, 2010). Ainda, as três vinícolas, visando sustentar a afirmação de que obedeciam à lei federal, exemplificaram algumas ações que fazem parte de seus processos de gestão ambiental.

Outro fato que pode ser ressaltado refere-se à importância do bom relacionamento entre órgãos fiscalizadores, como a Fundação Estadual de Proteção Ambiental Henrique Luiz Roessler (Fepam) e o Ministério da Agricultura, Pecuária e Abastecimento (Mapa), e as três vinícolas objeto de estudo. Infere-se que, ao manter um diálogo aberto com os referidos órgãos, as vinícolas recebem sugestões sobre práticas sustentáveis, tais como uso eficiente de agrotóxicos e fertilizantes, o que possibilita que, ao mesmo tempo, sejam reduzidos o impacto ambiental de suas ações junto ao meio ambiente e os custos inerentes aos processos produtivos (SZOLNOKI, 2013).

A segunda pressão diz respeito à crescente adoção da certificação ISO 14001:2004 por vinícolas nacionais e internacionais. Conforme a tipologia de Scott (2008), essa pressão pode ser concebida como de ordem normativa, visto que o crescente compartilhamento da referida certificação dentro da indústria vitivinícola abre espaço para que ocorra uma distinção entre vinícolas certificadas, as quais podem obter maior credibilidade frente ao mercado e à sociedade, e aquelas não certificadas, possivelmente menos creditadas e reconhecidas. A incidência dessa pressão pode ser vista nos relatos a seguir:

Tu sabes que eu leio, mas eu não fui atrás. Nem sempre os vinhos exportados são os de melhor qualidade. Aqueles que vão atrás disso irão querer ganhar prêmio, pra depois exportar. O pessoal da Universidade de Santa Cruz do Sul (Unisc) vem aqui e me incentiva a participar de programas de exportação, mas eu não quero (Vinícola A).

Eu não consegui terminar minha cantina. Eu não fiz a cantina pra ganhar dinheiro com vinho. Isso aqui é um hobby que eu tenho, o pessoal gasta com cavalo, gasta com jogo, e eu gasto com vinho. Só que agora que depois que eu registrei tudo isso aqui, só me deu prejuízo. Meu consultório que paga tudo. Sabia disso e sei disso. Sei que não vou ganhar dinheiro com vinho, só que vou ganha dinheiro por causa do vinho se eu fizer aqui um salão de eventos (Vinícola B).

Pra nós ainda não é o momento. A estrutura é pequena. Isso demanda muito tempo pra fazer os controles, a papelada. A gente optou pra participar de um projeto de certificação de qualidade junto com o Instituto Brasileiro do Vinho (Ibravin) chamado alimento seguro do SEBRAE. Até esse dias recebemos a resposta que fomos aprovados para receber a certificação de boas práticas de elaboração (BPE) e Análise de Perigos e Pontos Críticos de Controle (APPCC) (Vinícola C).

Percebe-se que a Vinícola A relaciona a obtenção da certificação com a entrada em mercados internacionais. Como o proprietário enfatiza que não pretende obter a certificação devido ao fato de não lhe interessar exportar seus produtos, entende-se que a resposta estratégica acionada pelo proprietário da Vinícola A, segundo a classificação de Oliver (1991), é desafiar, utilizando a tática despistar, pois o mesmo ignora essa pressão ao limitar a venda de seus produtos para o mercado nacional, que possui poucas vinícolas certificadas com o ISO 14001:2004 (WENDLER, 2009).

No que se refere à resposta dada pela Vinícola $B$, percebe-se que seu proprietário aciona a resposta estratégica de desafiar e a respectiva tática de despistar, visto que o mesmo ignora a certificação. Para o proprietário, seu negócio é um hobby, ou seja, algo que é realizado somente para preencher seu tempo de forma prazerosa. Desse modo, entende-se que o reconhecimento frente ao mercado vitivinícola com a certificação ISO 14001:2004 e, por consequência, a expan- 
são do negócio não é objetivo do proprietário da Vinícola B.

Analisando o conteúdo da resposta da Vinícola C, identifica-se que esta faz uso, segundo Oliver (1991), da resposta estratégica de comprometer devido ao fato de a empresa acreditar que, no momento, a obtenção da certificação ISO 14001:2004 é impraticável, pois o processo para obter a referida certificação é oneroso. Além do exposto, nota-se que a empresa utiliza a tática de pacificar, pois se conforma parcialmente às expectativas dos constituintes externos ao optar por adquirir certificações com respaldo nacional.

Percebe-se, assim, que as três vinícolas em análise não objetivam obter a certificação ISO 14001:2004. Diferentemente da homogeneidade verificada entre as repostas das três vinícolas frente à pressão 1 , quanto à pressão 2 , há indícios de isomorfismo apenas entre as estratégias da Vinícola A e da Vinícola B. Como há, segundo o relato do proprietário da Vinícola A, uma boa relação entre este e o proprietário da Vinícola $B$, pode se inferir que os mesmos trocam entre si pressuposições acerca da ocorrência de algum tipo de dificuldade e/ou do aumento de complexidade inerentes ao processo de expansão de seus negócios, o que os leva a não despender esforços para obter o reconhecimento oriundo da certificação (DIMAGGIO e POWELL, 1991).

Ainda é válido pressupor, apoiando-se nos pensamentos de Barata (2007) citado por Callado (2010), que um dos fatores que poderiam influenciar na decisão dos proprietários das Vinícolas A e B de não obter a certificação ISO14001: 2004 refere-se à recente difusão da gestão sustentável nos processos organizacionais das indústrias brasileiras. Outro evento que poderia estar impactando a decisão dos proprietários de não iniciar o processo para adquirir a certificação vincula-se ao fato de que a indústria vitivinícola, se comparada às indústrias mineral e química, é considerada como não poluidora, o que resulta em um menor controle e supervisão de suas práticas pelos constituintes (CHRIST e BURRITT, 2013).

Interessante ressaltar que a Vinícola $\mathrm{A}$ e a Vinícola $\mathrm{C}$, apesar de não terem interesse em obter a certificação ISO 14001:2004 por enquanto, concebem o valor de adotar a certificação para além da dimensão comercial, interpretando seu verdadeiro sentido, que é conscientizar as organizações de que se deve identificar e controlar o impacto ambiental de suas ações e melhorar constantemente seus desempenhos ambientais. Seguem, a seguir, os relatos das duas vinícolas:

Eu me importo sim com os processos rotineiros pra manter tudo limpo. Utilizo toucas, luvas e reutilizo garrafas, por exemplo. Eu posso até ter me criado sem esse costume, mas tem que fazer (Vinícola A).

Pra nós ainda não é o momento. Não que não estejamos preocupados com a parte ambiental (Vinícola C).

Dando seguimento às análises, apresenta-se, a seguir, a terceira pressão ambiental elencada no presente estudo: os consumidores de vinho estão, cada vez mais, preocupados com os efeitos das práticas de produção agrícola sobre o meio ambiente. Tomando como base a classificação de Scott (2008), essa pressão pode ser caracterizada como cultural-cognitiva, pois seus elementos são atualmente interpretados como constituintes da natureza da realidade social. Os relatos dos entrevistados acerca de seus posicionamentos estratégicos frente à essa pressão são apresentados a seguir:

Eu me preocupo com isso. A gente sempre procura fazer tratamento. Procuramos reaproveitar. Como eles conversam com a gente, uma das coisas que eles colocam é relacionada com a nossa preocupação com a higiene com os produtos que a gente utiliza, muitos vem assim e dizem que não querem vinho com química nenhuma. Daí a gente conversa e fala que estamos dentro da lei, controlamos o uso de produtos químicos no processo. $\mathrm{O}$ consumidor procura e também aprimora o gosto. Procuram vinhos melhores. Não só os comuns (Vinícola A). 
Sim, eu sou preocupadíssimo. Porque pra tu ter um bom vinho, a primeira coisa é uma parreira boa, bem cuidada. Depois é a higiene qualquer coisa. Se deixas a garrafa fechada e põe um produto do lado ela absorve, o vinho vai saí om aquele cheiro. Tem gente que tu derrama o vinho e ele já sabe se ele é velho ou se ele é novo. A pessoa que conhecer vinho, sente tudo isso (Vinícola B).

O pessoal não associa o vinho como um potencial poluidor. A preocupação maior é em relação à parte de resíduos e agroquímicos na uva. Aquilo que a gente utiliza nos vinhedos. A gente já trabalha com fornecedores corretos já que tem todo esse cuidado. Mas em relação à parte ambiental da vinícola, esse cuidado do consumidor a gente não nota (Vinícola C).

Nota-se que há novamente isomorfismo entre os proprietários das Vinícolas A e B. No entanto, no caso da terceira pressão, o isomorfismo deriva da percepção sobre as exigências dos consumidores por vinhos provenientes de vinícolas ambientalmente corretas. Como já comentado, pressupõe-se que os dois proprietários, por possuírem um bom relacionamento, substanciado por trocas de experiências e sugestões sobre aspectos inerentes a suas profissões, tendam a perceber as influências ambientais sob a mesma perspectiva (DIMAGGIO e POWELL, 1991).

O proprietário da Vinícola A e o proprietário da Vinícola B ressaltam o gerenciamento no uso de produtos químicos, a reutilização de vasilhames e os cuidados com higiene como formas de se adequar e atender às expectativas dos consumidores. Digno de nota é a interpretação de ambos os proprietários sobre o amadurecimento dos consumidores de vinho, os quais se mostram interessados em conhecer como as vinícolas gerem seus processos, assim como buscam produtos com maior qualidade. Verifica-se que os proprietários aquiescem frente às exigências e aos valores promulgados pelos consumidores no mercado (OLIVER, 1991).

A proprietária da Vinícola $C$ não percebe preocupação dos consumidores quanto ao potencial poluidor que as atividades vitivinícolas têm sobre o meio ambiente. No entanto, consciente que há certa preocupação com o uso de agroquímicos nas uvas, cujo uso em excesso poderia causar danos à saúde humana, a proprietária procura assegurar que seus fornecedores atendam a seus requerimentos de qualidade. Assim, percebe-se que a estratégia utilizada pela proprietária, tal como pelas demais vinícolas em estudo, é aquiescer, procurando obedecer aos requerimentos do mercado consumidor quanto ao uso racional e eficiente de agroquímicos. No Quadro 6, apresentam-se, de forma sintética, as três pressões delineadas no presente estudo e as respectivas respostas estratégicas de cada uma das vinícolas objeto de estudo.

Quadro 6: Síntese das repostas estratégicas das três vinícolas frente às três pressões delineadas.

\begin{tabular}{|l|c|c|c|}
\hline \multicolumn{1}{|c|}{ Pressões ambientais } & Vinícola A & Vinícola B & Vinícola C \\
\hline $\begin{array}{l}\text { 1. Lei n.o 9.605, de 12 de } \\
\text { fevereiro de 1998 }\end{array}$ & Aquiescer/ obedecer & Aquiescer/obedecer & Aquiescer/obedecer \\
\hline $\begin{array}{l}\text { 2. Difusão ISO 14001:2004 } \\
\text { 3. Consumidores preocu- } \\
\text { pados com a ação vitivi- } \\
\text { nícola sobre o meio am- } \\
\text { biente. }\end{array}$ & Aquiescer/obedecer & Aquiescer/obedecer & Aquiescer/obedecer \\
\hline
\end{tabular}

Fonte: elaborado pelos autores. 
Com a apresentação do Quadro 6, encerra-se a etapa de resultados e discussão. $\mathrm{Na}$ próxima seção, serão delineadas as conclusões a que o presente estudo chegou.

\section{CONSIDERAÇÕES FINAIS}

Neste trabalho, procurou-se identificar e analisar como três vinícolas da região central do Estado do Rio Grande do Sul respondem estrategicamente a três pressões ambientais que têm como foco o gerenciamento de práticas ambientalmente corretas.

Dado o caráter punitivo e obrigatório da Lei n.o 9.605, de 12 de fevereiro de 1998, notou-se que as três vinícolas em estudo aquiescem perante esta, pois, caso contrário, sofreriam com as penalidades e sanções prescritas na referida legislação. Além disso, o comportamento complacente e isomórfico das organizações pode ser explicado pela relação de dependência destas quanto aos órgãos fiscalizadores, como IBAMA e FEPAM, os quais sugerem e delineiam como as práticas e os processos devem ser realizados para que as organizações estejam em concordância com a legislação federal.

As organizações estudadas não possuem interesse em obter a certificação ISO 14001:2004, seja por falta de recursos e tempo ou porque os benefícios a serem adquiridos com a conquista da certificação não vão ao encontro de seus objetivos. Tanto buscando certificações com respaldo nacional ou preocupando-se com a higiene e reutilização de resíduos sólidos - tal como ressaltado pela Vinícola A - a falta de interesse em adquirir a certificação ISO 14001:2004 não implica descuido por parte das três vinícolas com o impacto de suas ações sobre o meio ambiente.

Segundo Guerra (2005), o comportamento de compra do consumidor pode ser caracterizado como um dos fatores fundamentais a ser levado em conta no processo de elaboração estratégica de qualquer organização, independente de qual for a atividade de negócio. Seguindo essa lógica, os vitivinicultores em estudo buscam, ao acionar a estratégia aquiescer, legitimar suas práticas frente aos consumidores que exigem produtos ambientalmente corretos. No entanto, analisando o conteúdo das repostas, verifica-se que os consumidores se encontram mais preocupados com a utilização de produtos químicos nos vinhos e vinhedos do que com a maneira como as vinícolas gerenciam seus processos de tratamento de efluentes, por exemplo.

Sem exceção e de forma isomórfica, mesmo que não busquem a certificação ISO 14001:2004 ou não percebam a preocupação do consumidor com relação à gestão ambiental, as vinícolas trabalham de maneira proativa, mantendo bom relacionamento com os órgãos fiscalizadores, para que suas ações não venham a afetar o meio ambiente. Tal achado encontra suporte no estudo de Marshall et al. (2010), o qual menciona que a visão dos stakeholders do mercado vitivinícola vincula as condições ambientais com a qualidade do vinho, fato que fornece um poderoso incentivo para que as vinícolas, independente do tamanho e da região, administrem de maneira proativa suas práticas para conservar o meio ambiente.

Mesmo que as entrevistas tenham sido realizadas em profundidade, ressalta-se que pelo fato de terem sido realizadas em corte transversal, limitações emergem pois os esquemas interpretativos dos empreendedores vitivinícolas foram postos a prova de forma instantânea. Assim, sugere-se que se investigue em outros contextos o modo como empreendedores vitivinícolas interpretam e respondem as pressões ambientais oriundas do governo, das associações de setor e dos consumidores. 


\section{REFERÊNCIAS}

BARDIN, Laurence. Análise de Conteúdo. Lisboa: Edições 70. 187p. 1977.

BIBLIOTECA DIGITAL DA CÂMARA DOS DEPUTADOS. Legislação brasileira sobre meio ambiente. 2010.

CALLADO, A. L. C. Modelo de mensuração de sustentabiliade empresarial: uma aplicação em vinícolas localizadas na Serra Gaúcha. Tese de doutorado-UFRGS-RS. Porto Alegre, 2010.

CHRIST, K. L.; BURRITT, R. L. Critical environmental concerns in wine production: an integrative review. Journal of Cleaner Production. N. 53. pp. 232 e 242, 2013.

DIMAGGIO, Paul J. e POWELL, Walter W. The iron cage revisited: institutional isomorphism and collective rationality in organizational fields. In: POWELL e DiMAGGIO. The new institutionalism in organizational analysis. pp. 63-82. Chicago: The University of Chicago Press.1991.

DODDS, R.; GRACI, S.; KO, S.; WALKER, L. What Drives Environmental Sustainability in the New Zealand Wine Industry? an Examination of Driving Factors and Practices. International Journal of Wine Business Research, Vol. $25 \mathrm{~N}$ 3. 2007.

DUTRA, L. C. Vermicompostar resíduos do vinho: um ícone no processo de educação. Monografia do curso de especialização em educação ambiental. Centro de ciências Rurais- Universidade Federal de Santa Maria. Santa Maria, RS. 75 p. 1998.

FLINT, D.J.; GOLICIC, S. L. Searching for competitive advantage through Sustainability: A qualitative study in the New Zealand wine industry. International Journal of Physical Distribution \& Logistics Management. Vol. 39 No. 10, pp. 841-860. 2009.

FONSECA, V. S.; SILVA, MACHADO-DA-SILVA,
C. L. M. Conversação entre abordagens da estratégia em organizações: escolha estratégica, cognição e instituição. O\&S. Organizações \& Sociedade, Salvador, v. 9, n.25, p. 93-110. 2002.

FORBES, S.L.; COHEN, D.A., CULLEN, R., WRATTEN, S.D.,FOUNTAIN, J. Consumer attitudes regarding environmentally sustainable wine: an exploratory study of the New Zealand marketplace. J. Clean. Prod. 17, pp. 1195-1212. 2010.

GABZDYLOVA, B.; RAFFENSPERGER, J.; CASTKA,P. Sustainability in the New Zealand wine industry: Drivers, stakeholders and practices. Journal of Cleaner Production. Vol. 17. N. 11: pp. 992-998. 2009.

GRAEFF, J. F. Pressões ambientais e respostas estratégicas na institucionalização do plantio direto no Paraná. Dissertação de mestrado. Universidade Federal do Paraná. Curitiba. 2005.

GUERRA, N. J. M. Análise do processo de decisão de compra do consumidor de vinho português: Avaliação de factores no contexto português. Dissertação de mestrado em Gestão de Empresas, especialização em Marketing. Universidade de Évora. Évora. 2005.

HASHIMOTO, N. Y. Pressões ambientais e respostas estratégicas: Um estudo no setor varejista Farmacêutico. Dissertação de Mestrado. Pontifícia Universidade Católica do Paraná. Curitiba. 2005.

HUGHEY, K. F. D.; TAIT, S. V.; O'CONNELL, M. J. Qualitative evaluation of three 'environmental management systems' in the New Zealand wine industry. Journal of Cleaner Production, Vol. 13. pp. 1175-1187. 2005.

INTERNATIONAL ORGANIZATION FOR STANDARDIZATION-OIV. About ISO. Disponível em: http://www.iso.org/iso/home/about.htm Acesso em: 20/06/2013. 
MACHADO-DA-SILVA, C. L. M.; FONSECA, V. S.; CRUBELLATE, J. M. Estrutura, agência e interpretação: elementos para uma abordagem recursiva do processo de institucionalização. RAC. Revista de Administração Contemporânea, Rio de Janeiro - RJ, v. 9, p. 9-39. 2005.

MARSHALL, R. S.; AKOORIE, M. E. M.; HAMANN, R., SINHA, P. Environmental practices in the wine industry: An empirical application of the theory of reasoned action and stakeholder theory in the United States and New Zealand. Journal of World Business, N. 45. pp. 405-414. 2010.

MEYER, J. W.; ROWAN, B. Institutionalized organizations: formal structure as myth and ceremony. American Journal of Sociology, $v$. 83, p. 340-363. 1977.

OLIVER, C. Strategic responses to institutional process. Academic of management review. Vol. 16. N. 1. 1991.

MIOLO WINE GRUPO. Pernod Ricard Brasil anuncia venda de Almadén para a Miolo Wine Group. Disponível em: http://www.miolo. com.br/noticias/pernod-ricard-brasil-anunciavenda-de-almaden-para-a-miolo-wine-group/. Acesso: 15/05/2013.

ORGANIZAÇÂO INTERNACIONAL DA VINHA E DO VINHO-OIV. Novena Asamblea General de la OIV: nuevas regulaciones para una producción de vino más segura y sostenible. Disponível em : http://www.oiv.int/oiv/info/ esassemblee2011 Acesso: 16/06/2013.

SINHA, P.; AKOORIE, M. Sustainable environmental practices in the New Zealand wine industry: an analysis of perceived institutional pressures and the role of exports.

J. Asia. Pac. Bus. N.11. pp. 50 - 74. 2010.

SCOTT, R. Institutions and organizations: ideas and interests. Estados Unidos. Sage Publications. 280 p. 2008.

SVeJenOVA, S.; MAZZA, C.; PLANELlAS, M.
Cooking up change in haute cuisine: Ferran Adrià as an institutional entrepreneur. Journal of Organizational Behavior. V.28 No.5. p. 539561. 2007.

SZOLNOKI, G. A cross-national comparison of sustainability in the wine industry. Journal of Cleaner production. Journal of Cleaner Production, Vol. 53. pp. 243 e 251. 2013.

VINÍCOLA AURORA. Certificações. Disponível em: http://www.vinicolaaurora.com.br/site/ certificacoes.php. Acesso: 12/05/2013.

WENDLER, D. F. Sistema de Gestão Ambiental aplicado a uma Vinícola:um estudo de caso. Dissertação de mestrado. Universidade Federal de Santa Maria, Santa Maria. 2009.

YIN, Robert K. Estudo de Caso: planejamento e métodos. 2. ed. Porto Alegre: Bookman. 212p. 2001. 